\title{
Novel applications of COX-2 inhibitors, metformin, and statins for the primary chemoprevention of breast cancer
}

\author{
Darren Micallef, Sarah Micallef, Pierre Schembri-Wismayer, Jean Calleja-Agius \\ Department of Anatomy, Faculty of Medicine and Surgery, University of Malta, Tal-Qroqq, Msida, Malta
}

\begin{abstract}
Recent evidence shows that commonly prescribed drugs, such as non-steroidal anti-inflammatory drugs (NSAIDs), metformin, and statins, may have beneficial roles in the primary chemoprevention of breast cancer. Therefore, these drugs could potentially be used in addition to the hormonal drugs currently used for this purpose (namely, selective estrogen receptor modulators and aromatase inhibitors) due to their alternative mechanisms of action. (J Turk Ger Gynecol Assoc 2016; 17: 214-23)
\end{abstract}

Keywords: Chemoprophylaxis, breast neoplasms, hydroxymethylglutaryl-CoA reductase inhibitors, metformin, anti-inflammatory agents, nonsteroidal

Received: 30 June, 2016 Accepted: 27 September, 2016

\section{Introduction}

Chemoprevention is defined as the use of pharmacological or natural agents that inhibit the development of a disease. In the case of breast cancer, the main chemopreventive agents used are selective estrogen receptor blockers (SERMs) and aromatase inhibitors (AIs) $(1,2)$.

Cyclooxygenase 2 (COX-2) inhibitors, non-steroidal antiinflammatory drugs (NSAIDs), metformin, and statins are drugs that have long been in clinical use. NSAIDs are used as anti-inflammatories, analgesics, and, in the case of aspirin, antithrombotics (3); metformin is used as an anti-hyperglycemic (4) and in the treatment of metabolic syndrome (5) and polycystic ovarian syndrome (PCOS); and statins are used for the primary and secondary prevention of cardiovascular disease by lowering cholesterol levels (6). Therefore, the safety profiles and adverse reaction profiles of these drugs are well understood. Thus, these drugs are good clinical candidates for further exploration of their mechanisms of action as applied to chemoprevention of breast cancer (7-9). Current studies regarding the novel application of these drugs have been critically analyzed with respect to their potential use in breast cancer chemoprevention. However, more research is needed to prove that these studies were adequately powered and thus are of good statistical significance, so that the use of these drugs can be considered as an option for chemoprevention of breast cancer in clinical practice.

\section{Search strategy}

The papers used as references in this review were identified using relevant keywords in related search engines such as Pubmed and Google Scholar, after performing a broader search regarding the chemoprevention of breast cancer and finding mentions of these drugs in other documents. The search terms used to identify these sources include "breast neoplasms," "breast cancer," "NSAIDs," "aspirin," "COX-2 inhibitors," "COX2 inhibitors," "cyclooxygenase 2 inhibitors," "metformin," "statins," and "HMG-CoA reductase inhibitors." The search results were then filtered, analyzed, and used as references in compiling this review.

\section{Non-steroidal anti-inflammatory drugs (NSAIDs)}

Various epidemiological studies have been conducted to establish a relationship between the use of NSAIDs and the incidence of breast cancer (10-12). The results of these studies are inconsistent; however, this inconsistency is most likely due to the fact that tumors have variable molecular properties (13).

All NSAIDs, such as aspirin and ibuprofen, inhibit both cyclooxygenase enzymes, largely with little or no selectivity for either enzyme. Aspirin irreversibly inhibits cyclooxygenase, while ibuprofen and other NSAIDs are reversible inhibitors. A meta-analysis has been conducted, focusing mainly on the effects of aspirin and ibuprofen (14). This meta-analysis included 16 case-control studies, 18 cohort studies, 3 case- 
control studies nested in well-defined cohorts, and one clinical trial, all of which were performed between 1966 and 2008, examining the association between the use of NSAIDs and the risk of breast cancer. The results of these studies were pooled and statistically analyzed separately for aspirin and ibuprofen. The conclusions of this meta-analysis were that aspirin use decreased the risk of breast cancer. It was also noted that high intake of aspirin did not strengthen this relationship. Similarly, use of ibuprofen led to a decrease in the risk of breast cancer; however, higher intake of ibuprofen did not strengthen this association (14).

This analysis also considered the effects that genetic polymorphisms of the COX-2 gene might have on these results; for example, the COX-2.847 mutation is associated with an even lower risk of breast cancer among patients using aspirin. Overall, NSAID use was associated with a lower risk of developing breast cancer.

More recently, the relationship of aspirin and ibuprofen use with the risk of breast cancer has been re-examined in the context of the different molecular subtypes of cancer (15). A total of 26,580 menopausal women aged 59 to 77 years were involved in this analysis. During follow-up through 2005, 1581 cases of breast cancer were observed. Estrogen receptor (ER) status was available for 1262 of these patients; 1060 were ER positive, and 202 were ER negative. Progesterone receptor status was available for 1237 cases; 910 were progesterone receptor positive, and 327 were progesterone receptor negative. The women were divided into groups based on frequency of NSAID intake. It was found that women who regularly took aspirin had an approximately 20\% lower risk of breast cancer than those who did not. In this study, higher frequency of aspirin intake was associated with lower risk (15), which contrasts with the results from the 2008 meta-analysis. These inverse associations of aspirin use were observed for ER+, ER-, PR+, and PRtumors, with the greatest correlations observed for ER + and PR+ tumors. However, in this study, no association was found between intake of non-aspirin NSAIDs and risk of breast cancer. One major limitation of this study was that the type of nonaspirin NSAID used was not specified; this may have masked any association between the intake of particular non-aspirin NSAIDs, such as ibuprofen, and the risk of breast cancer (15). It was further suggested that this difference is due to the fact that aspirin is an irreversible inhibitor of COX-2, while non-aspirin NSAIDs are reversible inhibitors.

The results of these various studies, although inconsistent and controversial, suggest that aspirin has chemopreventive potential; meanwhile, the chemopreventive potential of other NSAIDs remains to be clarified. Furthermore, in-depth examination of the relationship of NSAID consumption with various tumor subtypes, such as those in which COX-2 or epidermal growth factor receptor (EGFR) is upregulated, may shed light on the types of tumors that can be prevented with NSAIDs. These drugs would then be combined with other agents to achieve greater chemopreventive efficacy through combination treatment.

\section{COX-2 inhibitors}

NSAIDs not only inhibit COX-2, but also cyclooxygenase 1 (COX-1), which is responsible for regulating normal physiological functions; therefore, various adverse effects are associated with NSAID use. Side effects include stomach ulcers, nausea, vomiting, and prolonged bleeding after injury (16). For this reason, specific inhibitors of COX-2 have been developed. These include celecoxib and nimesulide, which are potent antiinflammatory agents that lack the associated adverse effects (16). However, a different side effect profile was noted, mostly related to the cardiovascular system. This includes a higher predisposition to hypertension, atherosclerosis, and thrombosis, resulting in a higher risk of myocardial infarctions and strokes (17); these are conditions for which risk is already increased in peri- and post-menopausal females.

COX-2 is induced in inflamed tissue from its constitutively active isoenzyme, COX-1. It is involved in the metabolism of arachidonic acid into prostaglandins and thromboxanes specific to the inflamed tissue; this mediates local vasodilation, edema, pain, and fever (16).

Because prostaglandins are crucial in mediating inflammatory response and the associated pain, various inhibitors of the cyclooxygenase enzymes have been identified or developed; their main target is pain relief.

Persistent inflammation may cause DNA damage, induce increased cellular proliferation to repair damaged tissue, and create an environment that is rich in cytokines and growth factors; all of these lead to tumorigenesis (18). Molecular links between cytokines and tumorigenesis have already been demonstrated for breast cancer and other conditions (19). In fact, COX-2 is highly overexpressed in numerous cancers, including breast, liver, colorectal, lung, and esophageal cancers $(20,21)$. Blocking persistent inflammation with NSAIDs and specific COX-2 inhibitors may therefore prove useful in the prevention of tumorigenesis.

Furthermore, a lower degree of prostaglandin synthesis leads to inhibition of the enzyme aromatase, which is responsible for the synthesis of estrogen. In fact, one of the major prostaglandins, $\mathrm{PGE}_{2}$, specifically induces the promoter II region on the aromatase gene (22). COX-2 inhibition has been shown to prevent estrogen-induced breast tumor formation to a greater extent than ibuprofen (a non-selective NSAID); thus, it demonstrates selective chemopreventive potential for ER-positive tumors (22).

The effects of ibuprofen were compared to those of celecoxib, particularly in their ability to inhibit carcinogenesis induced by 7,12-dimethylbenz(a)anthracene (DMBA) (Sigma-Aldrich; Darmstadt, Germany) in female Sprague-Dawley rats (22). These 50-day old rats were randomized into three groups, with 40 rats in each group. One group received powdered placebo with a standard diet, another group received $1500 \mathrm{mg} / \mathrm{kg}$ celecoxib with a standard diet, and the last group received 1500 $\mathrm{mg} / \mathrm{kg}$ ibuprofen with a standard diet. After seven days, all rats were given an intragastric dose of $15 \mathrm{mg}$ DMBA in $1.0 \mathrm{~mL}$ of sesame seed oil. The experimental and control diets were 
Table 1. Biochemical and molecular associations between type 2 diabetes mellitus and breast cancer

\begin{tabular}{|c|c|}
\hline & Biochemical Mechanisms (24) \\
\hline Insulin & $\begin{array}{l}\text { Insulin, which is secreted in increased amounts in type } 2 \text { diabetes, was shown to be mitogenic in breast tissue. } \\
\text { This is compounded by the fact that insulin receptors tend to be over-expressed in breast cancer cells }(25,26) \text {. } \\
\text { In fact, circulating level of C-peptide as a marker for insulin secretion has been shown to be positively associ } \\
\text { ated with risk of breast cancer in some studies (27-30). }\end{array}$ \\
\hline $\begin{array}{l}\text { Insulin-like growth } \\
\text { factor-1 (IGF-1) }\end{array}$ & $\begin{array}{l}\text { Increase in insulin secretion is accompanied by an increase in the serum level of IGF-1, which may also } \\
\text { contribute to tumor growth and thus can predict the risk of breast cancer in premenopausal women (31). }\end{array}$ \\
\hline \multirow[t]{2}{*}{$\begin{array}{l}\text { Estrogens and } \\
\text { androgens }\end{array}$} & $\begin{array}{l}\text { Increased levels of insulin also lead to higher levels of serum estrogens and androgens }(32,33) \text { through } \\
\text { inhibition of sex hormone-binding globulin }(34) \text {. Increased levels of estrogen and testosterone have been } \\
\text { associated with an increased risk of breast cancer in post-menopausal women }(35,36) \text {. }\end{array}$ \\
\hline & Molecular Mechanisms (37) \\
\hline $\begin{array}{l}\text { Insulin Receptor } \\
\text { (IR) }\end{array}$ & $\begin{array}{l}\text { IR is heterotetrameric protein consisting of four subunits; two subunits bind insulin, while the other two subunits } \\
\text { span the membrane, protrude into the cytosol, and have tyrosine kinase activity. Two isoforms of the insulin } \\
\text { receptor are produced by alternative splicing: IR-A (the fetal isoform) and IR-B. In most cancers, fetal IR-A } \\
\text { predominates because it mediates mitogenic rather than metabolic effects (37). }\end{array}$ \\
\hline $\begin{array}{l}\text { Insulin-like growth } \\
\text { factor-1 receptor } \\
\text { (IGF-1R) }\end{array}$ & $\begin{array}{l}\text { (IGF-1R) is } 60 \% \text { homologous with IR and also has tyrosine kinase activity upon ligand binding by IGF-1. It } \\
\text { promotes mitogenic, metastatic, and anti-apoptotic processes in breast cancer cells through the PI3K/Akt } \\
\text { pathway. Because insulin and IGF-1 can bind to both IR and IGF-1R with different affinities, both ligands can } \\
\text { enhance growth and survival (38). }\end{array}$ \\
\hline $\begin{array}{l}\text { Insulin receptor } \\
\text { substrate-1 (IRS-1) }\end{array}$ & $\begin{array}{l}\text { In type } 2 \text { diabetes, insulin resistance arises from the upregulation of cytokines and derivatives of free fatty acids. } \\
\text { These lead to activation of protein kinase C-zeta (PKC-zeta), which phosphorylates insulin receptor substrate-1 } \\
\text { (IRS-1), impairing its ability to activate the PI3K/Akt pathway upon ligand binding (39). Eventually, hyperglycemia } \\
\text { and high insulin levels develop. Activation of IGF-1R by these high insulin levels can therefore lead to activation } \\
\text { of the mitogenic and anti-apoptotic pathways, leading to an increased risk of cancer. Metabolic syndrome very } \\
\text { often results in these patients; this is characterized by hypertension, insulin resistance, obesity, and } \\
\text { dyslipidemia (40). }\end{array}$ \\
\hline
\end{tabular}

continued for 105 days before the experiment was stopped. The time of appearance of the first tumor in rats from each group was noted, while the size and location of the tumor was also assessed. At the end of the experiment, 127 palpable tumors were excised from the control rats (all adenocarcinomas) and 61 tumors were excised from rats treated with ibuprofen (all adenocarcinomas), while only 18 tumors were excised from rats treated with celecoxib (15 were adenocarcinomas, while 3 were non-malignant fibro-adenomas). Moreover, celecoxib was found to reduce the incidence of mammary cancer by $68 \%$, tumor burden (tumors/rat) by $86 \%$, and tumor volume by $81 \%$ compared to the control group. Only 13 of the $40(32 \%)$ rats treated with celecoxib developed tumors, while all of the control rats (100\%) developed tumors. Ibuprofen was also effective, but not as much as celecoxib; ibuprofen caused a $40 \%$ reduction in cancer risk, a $52 \%$ reduction in tumor burden, and a $57 \%$ reduction in tumor size. Moreover, the time for tumor development was prolonged with COX-2 inhibitor use. In the control group, the median time for detection of a tumor was 58 days after DMBA administration. In the celecoxib group, the median time was 95 days; in the ibuprofen group, it was 86 days.

It was also noted that celecoxib and ibuprofen appeared to have no adverse effects on rat liver, kidneys, stomach, and intestines. In humans, however, there are concerns that drugs that inhibition of COX-2 can lead to severe cardiovascular adverse effects.
Nonetheless, the use of COX-2 inhibitors in patients at low risk for heart disease appears to be safe (21).

The results from this experiment show that celecoxib may be a very useful chemopreventive agent; they also support the role that COX-2 inhibitors, including the general NSAID ibuprofen, may play in reducing the risk of breast cancer.

\section{Metformin}

Diabetes has been associated with an increased risk of developing cancer; a recent meta-analysis involving 20 studies demonstrated the actual relationship between diabetes and breast cancer (23). This meta-analysis showed that women with diabetes have a $20 \%$ increased risk of developing breast cancer compared to non-diabetic women. A more recent meta-analysis suggested that diabetic women have a $23 \%$ higher risk of breast cancer, particularly menopausal women, while diabetes was also found to increase breast cancer mortality overall (24). Interestingly, the association between diabetes and breast cancer was strongest in Europe, followed by America, while it was non-significant in Asia (24). The biochemical and molecular associations between type 2 diabetes mellitus and breast cancer are outlined in Table 1 (2542 ), while the structure, uses, outcomes, and adverse reactions of metformin are shown in Table $2(4,5,38,42,43)$.

Metformin increases the effectiveness of neoadjuvant chemotherapy in breast cancer patients (44). In one particular study, 
Table 2. Metformin: Structure, uses, outcomes, and adverse reactions

\begin{tabular}{|c|c|}
\hline & Metformin \\
\hline Structure & Semi-synthetic biguanide with two methyl groups attached to its nitrogen nucleus. \\
\hline Uses & Approved for use to treat hyperglycemia (3), metabolic syndrome (4), and PCOS (41). \\
\hline \multirow{4}{*}{ Outcomes (37) } & Inhibits gluconeogenesis in the liver without stimulating insulin secretion. \\
\hline & $\begin{array}{l}\text { Mediates increased uptake of glucose by skeletal muscle and adipose tissue, leading to a decrease in blood } \\
\text { glucose levels. }\end{array}$ \\
\hline & $\begin{array}{l}\text { Increases the affinity of the insulin receptor for insulin, thus improving insulin resistance and leading to } \\
\text { reduction in insulin levels of approximately } 25 \% \text { to } 33 \% \text { after several days. }\end{array}$ \\
\hline & Decreases circulating levels of cholesterol, LDLs, and triglycerides. \\
\hline $\begin{array}{l}\text { Side effects } \\
(37,42)\end{array}$ & $\begin{array}{l}\text { Mild gastrointestinal effects (30\%) and metallic taste (3\%), which are reversible with persistent use, and } \\
\text { decreased levels of vitamin B12 (6\%). }\end{array}$ \\
\hline
\end{tabular}

the pathologic complete response (pCR), i.e., the absence of residual tumor at the time of surgery, was assessed for these patients (44). The difference in PCR between the non-diabetic group (16\%) and the non-metformin group (8\%) was significant, as was the difference between the metformin (24\%) and nonmetformin $(8 \%)$ groups. In contrast, the difference between the non-diabetic (16\%) and metformin (24\%) groups, although numerically evident, did not attain clinical significance. This proved that the anti-proliferative characteristics of metformin impair tumor development. Moreover, because insulin use was twice as great in the non-metformin group compared to the metformin group (33\% and 16\%, respectively), it was observed that higher insulin levels were associated with decreased pCR (44). However, overall disease recurrence did not differ significantly between the groups, and both diabetic groups had worse overall survival than the non-diabetic group (45).

Various epidemiological studies have demonstrated a lower incidence of mortality from cancer in diabetic patients receiving low-dose metformin. A large meta-analysis (46) demonstrated that the overall cancer rate decreased by $31 \%$ in patients taking metformin compared to patients taking other anti-diabetic drugs. This difference was significant for pancreatic and liver cancer but was not significant for colon, breast, and prostate cancer.

This supports earlier results that showed that cancer incidence decreased by more than $50 \%$ in patients who had been taking metformin for over 4 years (47). In 2012, another meta-analysis confirmed the beneficial effects of metformin for decreasing the risk of cancer and reducing overall cancer mortality (48). The mechanisms underlying the action of metformin are complex and are far from fully understood. The beneficial effects of metformin may be indirect (through insulin), or it may directly affect the proliferation and growth of cells (45). Many mechanisms of metformin action have been proposed, as outlined in Table 3 (3, 45, 49-54).

Preclinical models show that metformin can lower the incidence of breast cancer (55). Metformin affects ER+ and ER-cell lines as well as human epidermal growth factor receptor 2 (HER-2) normal and abnormal cancer cell lines; it inhibits cell proliferation and causes cell cycle arrest at the G1 checkpoint, probably through reduction of cyclin D1 and E2F1 expression. It also inhibits MAPK, Akt, and mTOR activity in all of these cell lines. However, metformin does not induce apoptosis. Furthermore, at high doses, metformin was found to reduce HER-2 expression in cancer cells overexpressing HER-2; at lower doses, it was found to inhibit HER-2 tyrosine kinase activity (55).

As demonstrated in preclinical models, metformin at a low dose can inhibit the tyrosine kinase activity of the HER-2 receptor; also, a high dose of metformin can downregulate HER-2 (38). Thus, therapeutically combining metformin with the antiHER-2 monoclonal antibody trastuzumab may be very efficient to eliminate stem/progenitor cell populations with amplified HER-2. This is particularly due to the fact that metformin can prevent resistance to trastuzumab treatment; this is very often mediated by high levels of IGF and insulin, which bind to their respective receptors and induce cellular proliferation, inhibition of apoptosis, angiogenesis, and metastasis. Metformin can decrease circulating insulin and IGF levels and can thus disrupt this alternative pathway for tumor development.

In the prevention setting, metformin can therefore regulate the rate of proliferation of tumor progenitor cells in premalignant lesions, thus preventing or delaying malignant tumor formation (38). Furthermore, by regulating proliferation of dormant cancer stem cells, metformin can also prevent recurrence of breast cancer; thus, it may be effective for secondary prevention of breast cancer.

Cancer is the second leading cause of death worldwide, while diabetes is the twelfth (48). Considering that the prevalence of diabetes is constantly increasing, the use of metformin as both an anti-diabetic drug as well as a chemopreventive agent for cancer will have numerous beneficial implications and positive results. 
Table 3. Proposed mechanisms of action of metformin

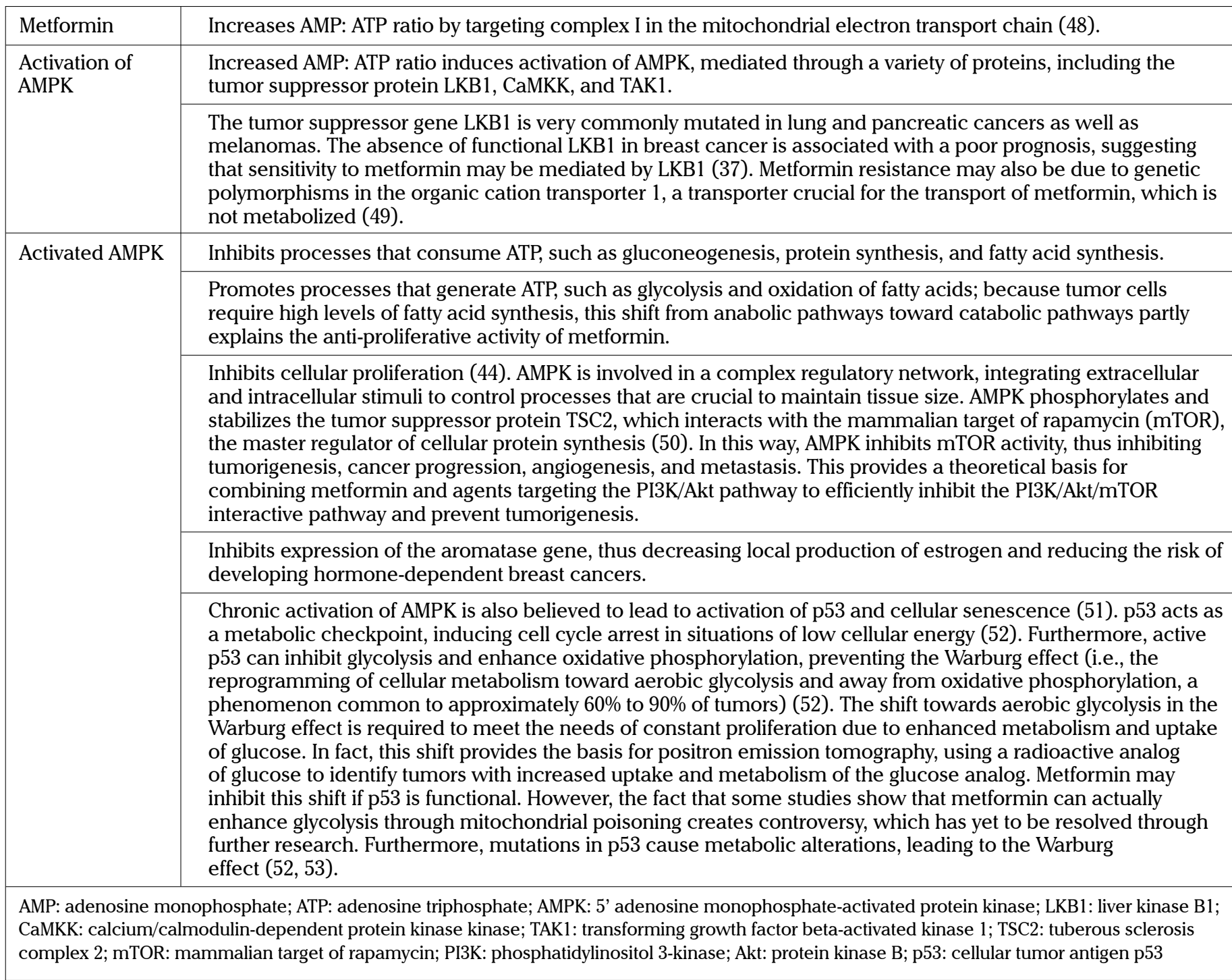

\section{Statins}

The anti-atherosclerotic decrease of plasma LDL caused by statins through inhibition of the conversion of 3-hydroxy3-methylglutaryl-coenzyme A (HMG-CoA) to mevalonate in cholesterol synthesis has been well studied and documented (56). In fact, statins are the most potent class of drugs for primary and secondary prevention of cardiovascular injury.

Considering the concept that combining statins and estrogen may have synergistic effects for improving lipid profiles in postmenopausal women, investigations have been conducted to determine whether statins can reduce the incidence of breast cancer, the most controversial adverse effect associated with estrogen therapy (57).

Interestingly, a variety of preclinical studies show that statins can not only prevent cardiovascular diseases but may also inhibit cancer growth and development, although the actual mechanisms have not yet been completely elucidated $(57,58)$. A proposed mechanism of action for statins is outlined in Figure
1 (59); this shows the mevalonate pathway on which statins (as HMG CoA inhibitors) act. This is also linked to various in vitro and in vivo studies, which are summarized in Table 4 (57-59). Statins can also interfere with microdomain formation in endothelial cells and inhibit oxidative stress pathways, both enzymatically and non-enzymatically. Furthermore, statins can upregulate endothelial nitric oxide synthase, eNOS, improving endothelial function (60).

In an in vitro study, the effects of statins on the cellular proliferation of breast cancer cell lines were studied, both alone and in combination with estradiol (57). The breast cancer cell lines, MCF-7 (ER+) and MDA-MB 231 (ER-), were cultured in the presence of the lipophilic statins atorvastatin, lovastatin, fluvastatin, simvastatin, and hydrophilic pravastatin, both alone and in combination with estrogen. The results showed that all statins, with the exception of pravastatin, significantly inhibited cellular proliferation in both cell lines after four days of culture; this association was dose-dependent. The inhibitory values 
Table 4. Effects of statins as outlined in Figure 1

\begin{tabular}{|c|c|}
\hline Endothelial cells & $\begin{array}{l}\text { Interfere with microdomain formation and inhibit oxidative stress pathways, both enzymatically and } \\
\text { non-enzymatically. Statins can also upregulate endothelial nitric oxide synthase, eNOS, improving endothelial } \\
\text { function (59). }\end{array}$ \\
\hline \multirow[t]{4}{*}{$\begin{array}{l}\text { In vitro breast } \\
\text { cancer cells }\end{array}$} & $\begin{array}{l}\text { In an in vitro study, the effects of statins on cellular proliferation of breast cancer cell lines were studied, both } \\
\text { alone and in combination with estradiol (56). The breast cancer cell lines, MCF-7 (ER+ cells) and MDA-MB } 231 \\
\text { (ER-), were cultured in the presence of the lipophilic statins atorvastatin, lovastatin, fluvastatin, and simvastatin, } \\
\text { as well as the hydrophilic statin pravastatin, both alone and in combination with estrogen. }\end{array}$ \\
\hline & $\begin{array}{l}\text { In the presence of estrogen, all statins equally inhibited cellular proliferation in ER+ cells. However, the statins } \\
\text { were not completely successful in preventing cellular proliferation in the presence of stimulating estradiol (56). }\end{array}$ \\
\hline & $\begin{array}{l}\text { Further in vitro studies demonstrate the ability of the lipophilic statins to prevent cellular proliferation in tumor } \\
\text { cell lines that are hormone receptor-positive and HER-2-negative (MCF-7), hormone receptor-negative and } \\
\text { HER-2-positive (SKBr3), and double negative (MDA-231) (57). }\end{array}$ \\
\hline & 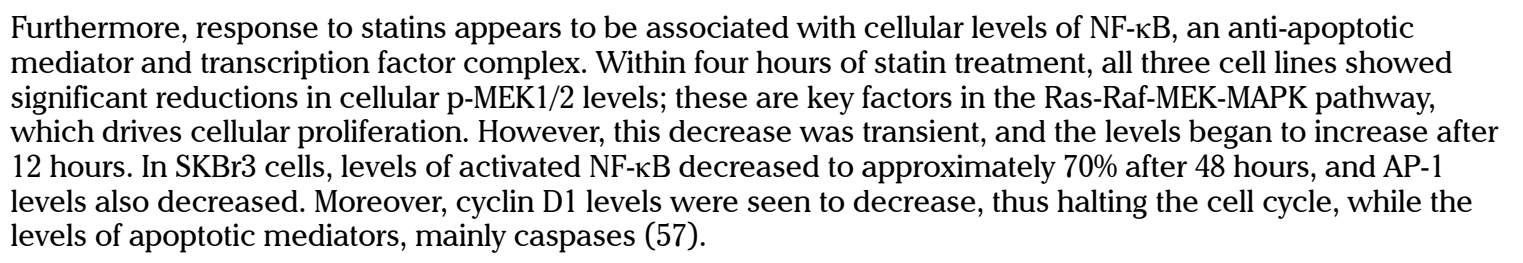 \\
\hline $\begin{array}{l}\text { In vivo (mice } \\
\text { inoculated with } \\
\text { MCNeuA cells) }\end{array}$ & $\begin{array}{l}\text { In vivo, mice inoculated with MCNeuA cells (HER-2+, ER-), benefit from oral treatment of simvastatin at } 1 \text { to } 2 \\
\mathrm{mg} / \mathrm{kg} \text { body weight daily (equivalent to approximately } 5 \text { to } 10 \mathrm{mg} \text { daily in humans) (57). Tumors from mice } \\
\text { treated with statins appeared to be richer in caspases, showing enhanced apoptosis (57). }\end{array}$ \\
\hline \multicolumn{2}{|c|}{$\begin{array}{l}\text { eNOS: endothelial nitric oxide synthase; ER: estrogen receptor; MCF-7: Michigan Cancer Foundation-7 cell line; MDA-MB 231: cell line with breast ad- } \\
\text { enocarcinoma metastases derived from pleural effusion; HER-2: human epidermal growth factor receptor 2; SKBr3: cell line with breast adenocarci- } \\
\text { noma metastases derived from pleural effusion; Ras: rat sarcoma gene; NF-kB: nuclear factor } \kappa B \text {; Raf: rapidly accelerated fibrosarcoma kinase; MEK: } \\
\text { mitogen-activated protein kinase kinase; MAPK: mitogen-activated protein kinase; MCNeuA: mammary carcinoma from Neu transgenic mouse A }\end{array}$} \\
\hline
\end{tabular}

ranged from $10 \%$ to $90 \%$; the inhibition was greater in ER- cells. In ER+ cells, atorvastatin was a less potent inhibitor than the other statins. In the presence of estrogen, all statins showed equal inhibition of cellular proliferation in ER+ cells. However, the statins were not completely successful in preventing cellular proliferation in the presence of stimulating estradiol (57). Further in vitro studies have demonstrated the ability of the lipophilic statins to prevent cellular proliferation in tumor cell lines that are hormone receptor-positive and HER-2-negative (MCF7), hormone receptor-negative and HER-2-positive (SKBr3), or double negative (MDA-231) (58). In vitro, the hydrophilic statin pravastatin showed no inhibitory effects on any cell line. In contrast, the lipophilic statins fluvastatin, lovastatin, and simvastatin showed significant inhibition of cell growth, particularly in cells with activated Ras and HER-2 pathways. Furthermore, response to statins appeared to be associated with cellular levels of NF- $\mathrm{KB}$, an anti-apoptotic mediator and transcription factor complex. Within four hours of statin treatment, all three cell lines showed significant reductions in cellular p-MEK1/2 levels, a key player in the Ras-Raf-MEK-MAPK pathway that drives cel- lular proliferation. However, this decrease was transient, and p-MEK1/2 levels began to increase after 12 hours. In SKBr3 cells, levels of activated NF- $\mathrm{BB}$ decreased to approximately $70 \%$ after 48 hours; AP-1 levels also decreased. Moreover, levels of cyclin D1 were seen to decrease, thus halting the cell cycle, while the levels of apoptotic mediators, mainly caspases (58).

In an in vivo study, mice inoculated with MCNeuA cells (HER$2+$, ER-) benefitted from oral treatment of simvastatin at 1 to $2 \mathrm{mg} / \mathrm{kg}$ body weight daily (equivalent to approximately 5 to $10 \mathrm{mg}$ daily in humans) (58). Tumors from mice treated with statins appeared to be richer in caspases, showing enhanced apoptosis (58).

Epidemiological studies provide conflicting evidence. Numerous studies have demonstrated that statin use is associated with a lower risk of developing cancer (61-64), while other studies describe an increased risk $(65,66)$. Bonovas et al. (67) conducted a meta-analysis of 7 randomized trials and 9 observational trials; they concluded that statin use did not affect the risk of developing breast cancer. The overall incidence of breast cancer was calculated to be $1.55 \%$ in the treatment group receiving 


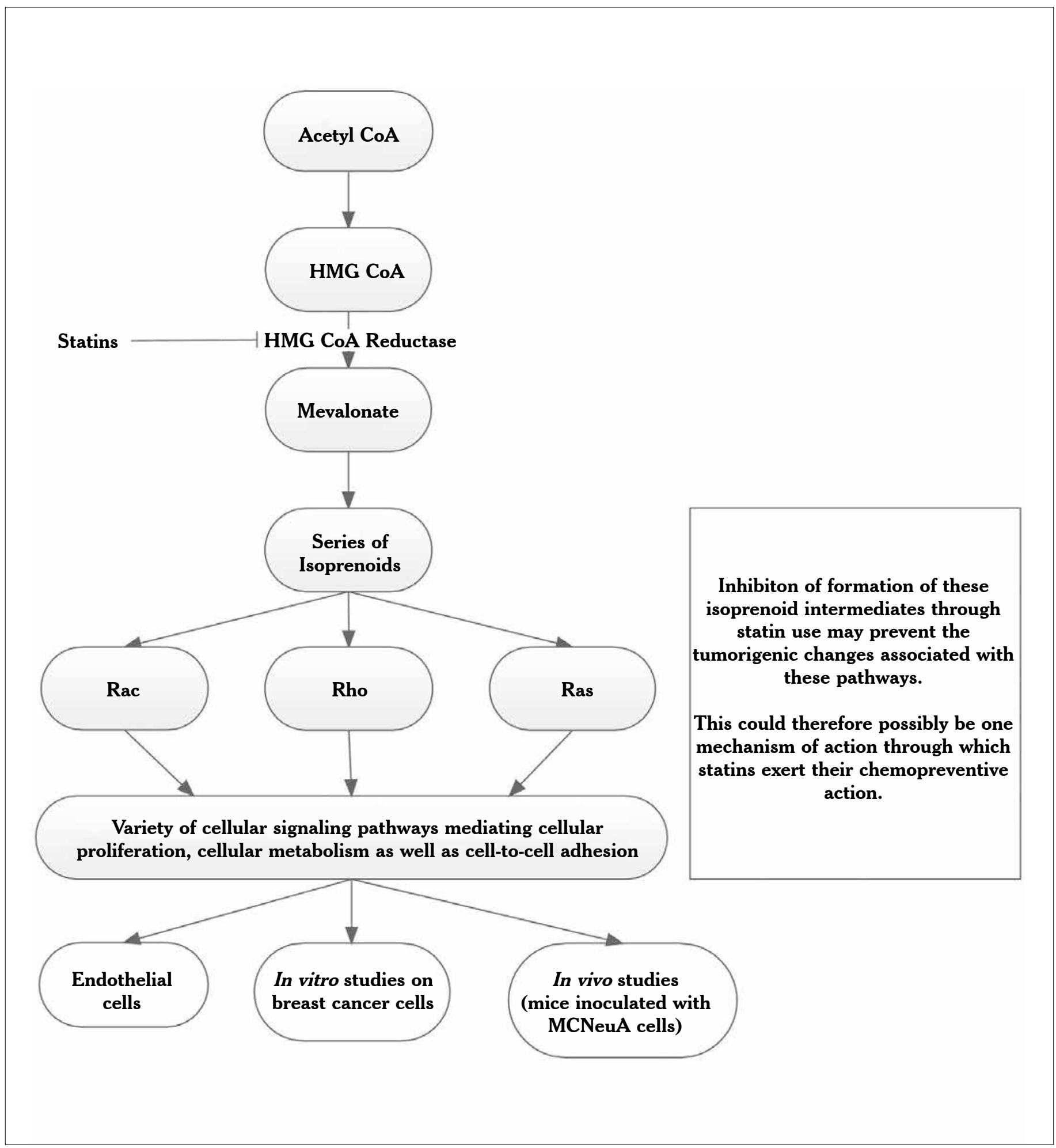

Figure 1. Proposed mechanism of action of statins (59)

statins (132 cases) and $1.43 \%$ in the non-treatment group (122 cases). This difference was not found to be statistically significant. However, the trials included in this meta-analysis mainly focused on the effects of statins on cardiovascular disease; the dosages were set only in this regard, and follow-up was relatively short. The effects of long-term statin use and the incidence of breast cancer could not be identified, which may have affected the observed association between statin use and risk of breast cancer. Furthermore, this meta-analysis included the use of both lipophilic and hydrophobic statins; the latter cannot 
permeate the cell membrane and thus do not exert activity on cellular proliferation and motility. This may have also led to the calculated lack of association between statin use and risk of breast cancer.

More recently, a trial was performed to test the chemopreventive abilities of fluvastatin in women with diagnosed DCIS or stage 1 breast carcinoma. Patients were randomized to receive either $80 \mathrm{mg}$ daily or $20 \mathrm{mg}$ daily of fluvastatin for 3 to 6 weeks prior to surgery. The results showed that fluvastatin was most effective in patients with high grade (poorly differentiated) tumors. The proliferation of these tumors decreased by a median of $7.2 \%$, while in low grade tumors, this decrease was only $0.3 \%$; the difference between the two was statistically significant. Overall, tumor apoptosis increased in $38 \%$ of patients, remained the same in $41 \%$, and decreased in $21 \%$; high grade tumors showed an increase in apoptosis (68).

The preclinical, clinical, and epidemiological results show that statins can likely reduce the incidence of breast cancer and may have anti-tumor potential. However, controversy persists. Further investigation is still required to identify whether statin use is truly associated with reduced incidence of breast cancer, the magnitude of this association, and the class of patients in which it is most likely to be prevalent.

In conclusion, because the abovementioned drugs have different mechanisms of action than the endocrine drugs currently used as chemopreventive agents (mainly SERMs and AIs), they may be useful as chemopreventive agents in non-responders to conventional chemoprevention. This makes sense, especially when considering that these same drugs are also being used to treat concurrent, prevalent conditions such as diabetes and hyperlipidemia. However, further studies to evaluate the chemopreventive potency of these drugs compared to current chemopreventive strategies are required to clarify this controversial issue. These studies may associate these drugs with chemopreventive benefits in breast cancer and may also identify which patient groups are likely to benefit from this novel application of these drugs. The desired result would be the clinical implementation of these further studies, thus providing another mechanism of chemoprevention of breast cancer and reducing polypharmacy in the respective patients; thus, the instance of adverse drug reactions and drug-drug interactions would decrease.

\section{Ethics Committee Approval: N/A.}

Informed Consent: N/A.

Peer-review: Externally peer-reviewed.

Author Contributions: Concept - J.C.A.; Design - D.M., S.M.; Supervision - J.C.A.; Resources - D.M., S.M., J.C.A.; Materials - D.M., S.M.; Data Collection and/or Processing - D.M., S.M.; Analysis and/or Interpretation - D.M., J.C.A., P.S.W.; Literature Search - D.M., S.M.; Writing Manuscript D.M., S.M.; Critical Review - J.C.A., P.S.W.

Conflict of Interest: No conflict of interest was declared by the authors.

Financial Disclosure: The authors declared that this study has received no financial support.

\section{References}

1. Cazzaniga M, Bonanni B. Breast cancer chemoprevention: old and new approaches. J Biomed Biotechnol 2012; 2012: 985620.

2. Micallef S, Micallef D, Schembri-Wismayer P, Brincat MP, Calleja-Agius J. Chemoprevention of breast cancer among women at elevated risk as defined by Gail Score. Minerva Ginecol 2015; 67: 335-52.

3. Russell R. Non-steroidal anti-inflammatory drugs and gastrointestinal damage-problems and solutions. Postgrad Med J 2001; 77: 82-8.

4. Nathan DM, Buse JB, Davidson MB, Heine RJ, Holman RR, Sherwin $\mathrm{R}$, et al. Management of hyperglycemia in type 2 diabetes: A consensus algorithm for the initiation and adjustment of therapy a consensus statement from the American Diabetes Association and the European Association for the study of diabetes. Diabetes Care 2006; 29: 1963-72.

5. Emili A, Abushomar H, Nair K. Treating metabolic syndrome Lifestyle change or medication? Can Fam Physician 2007; 53: 1203-5.

6. Taylor F, Huffman MD, Macedo AF, Moore T, Burke M, Davey Smith $\mathrm{G}$, et al. Statins for the primary prevention of cardiovascular disease. Cochrane Database Syst Rev 2013; CD004816.

7. Santa-Maria CA, Stearns V. Statins and breast cancer: future directions in chemoprevention. Curr Breast Cancer Rep 2013; 5: 161-9.

8. Cazzaniga M, Bonanni B, Guerrieri-Gonzaga A, Decensi A. Is it time to test metformin in breast cancer clinical trials? Cancer Epidemiol Biomarkers Prev 2009; 18: 701-5.

9. Yiannakopoulou EC. Aspirin and NSAIDs for breast cancer chemoprevention. European Journal of Cancer Prevention: 2015; 24: 416-21.

10. Harris RE, Alshafie GA, Abou-Issa H, Seibert K. Chemoprevention of breast cancer in rats by celecoxib, a cyclooxygenase 2 inhibitor. Cancer Res 2000; 60: 2101-3.

11. Harris RE, Namboodiri KK, Farrar WB. Nonsteroidal antiinflammatory drugs and breast cancer. Epidemiology 1996; 7: 203-5.

12. Agrawal A, Fentiman I. NSAIDs and breast cancer: a possible prevention and treatment strategy. Int J Clin Pract 2008; 62: 444-9.

13. Perou CM, Sørlie T, Eisen MB, van de Rijn M, Jeffrey SS, Rees CA, et al. Molecular portraits of human breast tumours. Nature 2000; 406 : 747-52.

14. Takkouche B, Regueira-Mendez C, Etminan M. Breast cancer and use of nonsteroidal anti-inflammatory drugs: a meta-analysis. J Natl Cancer Inst 2008; 100: 1439-47.

15. Bardia A, Olson JE, Vachon CM, Lazovich D, Vierkant RA, Wang AH, et al. Effect of aspirin and other NSAIDs on postmenopausal breast cancer incidence by hormone receptor status: results from a prospective cohort study. Breast Cancer Res Treat 2011; 126: 149-55.

16. Lieberman M, Marks AD. Marks' Basic Medical Biochemistry: A Clinical Approach: Wolters Kluwer Health/Lippincott Williams \& Wilkins; 2009.p 847-62.

17. Funk CD, FitzGerald GA. COX-2 inhibitors and cardiovascular risk. J Cardiovasc Pharmacol 2007; 50: 470-9.

18. Schottenfeld D, Beebe-Dimmer J. Chronic inflammation: a common and important factor in the pathogenesis of neoplasia. CA Cancer J Clin 2006; 56: 69-83.

19. Pollacco J, Sacco K, Portelli M, Schembri-Wismayer P, Calleja-Agius J. Molecular links between endometriosis and cancer. Gynecol Endocrinol 2012; 28: 577-81.

20. Brasky TM, Bonner MR, Moysich KB, Ambrosone CB, Nie J, Tao MH, et al. Non-steroidal anti-inflammatory drugs (NSAIDs) and breast cancer risk: differences by molecular subtype. Cancer Causes Control 2011; 22: 965-75. 
21. Uray IP, Brown PH. Chemoprevention of hormone receptor-negative breast cancer: new approaches needed. Recent Results Cancer Res 2011; 188: 147-62.

22. Harris RE, Alshafie GA, Abou-Issa H, Seibert K. Chemoprevention of breast cancer in rats by celecoxib, a cyclooxygenase 2 inhibitor. Cancer Res 2000; 60: 2101-3.

23. Larsson SC, Mantzoros CS, Wolk A. Diabetes mellitus and risk of breast cancer: a meta-analysis. Int J Cancer 2007; 121: 856-62.

24. Liao S, Li J, Wei W, Wang L, Zhang Y, Li J, et al. Association between diabetes mellitus and breast cancer risk: a meta-analysis of the literature. Asian Pac J Cancer Prev 2011; 12: 1061-5.

25. Larsson SC, Mantzoros CS, Wolk A. Diabetes mellitus and risk of breast cancer: A meta-analysis. Int J Cancer 2007; 121: 856-62.

26. Belfiore A, Frittitta L, Costantino A, Frasca F, Pandini G, Sciacca L, et al. Insulin receptors in breast cancer. Ann N Y Acad Sci 1996; 784: 173-88.

27. Papa V, Belfiore A. Insulin receptors in breast cancer: biological and clinical role. J Endocrinol Invest 1996; 19: 324-33.

28. Hirose K, Toyama T, Iwata H, Takezaki T, Hamajima N, Tajima K. Insulin, insulin-like growth factor-I and breast cancer risk in Japanese women. Asian Pac J Cancer Prev 2003; 4: 239-46.

29. Lawlor DA, Smith GD, Ebrahim S. Hyperinsulinaemia and increased risk of breast cancer: findings from the British Women's Heart and Health Study. Cancer Causes Control 2004; 15: 267-75.

30. Verheus M, Peeters PH, Rinaldi S, Dossus L, Biessy C, Olsen A, et al. Serum C-peptide levels and breast cancer risk: Results from the European prospective investigation into cancer and nutrition (EPIC). Int J Cancer 2006; 119: 659-67.

31. Yang G, Lu G, Jin F, Dai Q, Best R, Shu XO, et al. Population-based, case-control study of blood C-peptide level and breast cancer risk. Cancer Epidemiol Biomarkers Prev 2001; 10: 1207-11.

32. Renehan AG, Harvie M, Howell A. Insulin-like growth factor (IGF)-I, IGF binding protein-3, and breast cancer risk: eight years on. Endocr Relat Cancer 2006; 13: 273-8.

33. Nyholm H, Djursing H, Hagen C, Agner T, Bennett P, Svenstrup B. Androgens and estrogens in postmenopausal insulin-treated diabetic women. J Clin Endocrinol Metab 1989; 69: 946-9.

34. Quinn M, Ruffe H, Brown J, Ennis G. Circulating gonadotropins and urinary oestrogens in postmenopausal diabetic women. Aust N Z J Obstet Gynaecol 1981; 21: 234-6.

35. Plymate SR, Hoop RC, Jones RE, Matej LA. Regulation of sex hormone-binding globulin production by growth factors. Metabolism 1990; 39: 967-70.

36. Kaaks R, Rinaldi S, Key T, Berrino F, Peeters P, Biessy C, et al. Postmenopausal serum androgens, oestrogens and breast cancer risk: the European prospective investigation into cancer and nutrition. Endocr Relat Cancer 2005; 12: 1071-82.

37. Key T, Appleby P, Barnes I, Reeves G. Endogenous sex hormones and breast cancer in postmenopausal women: reanalysis of nine prospective studies. J Natl Cancer Inst 2002; 94: 606-16.

38. Del Barco S, Vazquez-Martin A, Cufi S, Oliveras-Ferraros C, BoschBarrera J, Joven J, et al. Metformin: multi-faceted protection against cancer. Oncotarget 2011; 2: 896-917.

39. Vigneri P, Frasca F, Sciacca L, Pandini G, Vigneri R. Diabetes and cancer. Endocr Relat Cancer 2009; 16: 1103-23.

40. Ravichandran LV, Esposito DL, Chen J, Quon MJ. Protein kinase C-zeta phosphorylates insulin receptor substrate-1 and impairs its ability to activate phosphatidylinositol 3-kinase in response to insulin. J Biol Chem 2001; 276: 3543-9.
41. Pasanisi P, Berrino F, De Petris M, Venturelli E, Mastroianni A, Panico $\mathrm{S}$. Metabolic syndrome as a prognostic factor for breast cancer recurrences. Int J Cancer 2006; 119: 236-8.

42. Lashen $\mathrm{H}$. Role of metformin in the management of polycystic ovary syndrome. Ther Adv Endocrinol Metab 2010; 1: 117-28.

43. Hermann LS. Metformin: a review of its pharmacological properties and therapeutic use. Diabete Metab 1979; 5: 233-45.

44. Jiralerspong S, Palla SL, Giordano SH, Meric-Bernstam F, Liedtke C, Barnett CM, et al. Metformin and pathologic complete responses to neoadjuvant chemotherapy in diabetic patients with breast cancer. J Clin Oncol 2009; 27: 3297-302.

45. Goodwin PJ, Ligibel JA, Stambolic V. Metformin in breast cancer: time for action. J Clin Oncol 2009; 27: 3271-3.

46. Decensi A, Puntoni M, Goodwin P, Cazzaniga M, Gennari A, Bonanni B, et al. Metformin and cancer risk in diabetic patients: a systematic review and meta-analysis. Cancer Prev Res 2010; 3: 1451-61.

47. Evans JM, Donnelly LA, Emslie-Smith AM, Alessi DR, Morris AD. Metformin and reduced risk of cancer in diabetic patients. BMJ 2005; 330: 1304-5.

48. Noto H, Goto A, Tsujimoto T, Noda M. Cancer risk in diabetic patients treated with metformin: a systematic review and meta-analysis. PloS One 2012; 7: e33411.

49. Zhu Z, Jiang W, Thompson MD, McGinley JN, Thompson HJ. Metformin as an energy restriction mimetic agent for breast cancer prevention. J Carcinog 2011; 10: 17.

50. Takane H, Shikata E, Otsubo K, Higuchi S, Ieiri I. Polymorphism in human organic cation transporters and metformin action. Pharmacogenomics 2008; 9: 415-22.

51. Inoki K, Zhu T, Guan KL. TSC2 mediates cellular energy response to control cell growth and survival. Cell 2003; 115: 577-90.

52. Vazquez-Martin A, Oliveras-Ferraros C, Lopez-Bonet E, Menendez JA. AMPK: Evidence for an energy-sensing cytokinetic tumor suppressor. Cell Cycle 2009; 8: 3679-83.

53. Pecorino L. Molecular Biology of Cancer: Mechanisms, Targets, and Therapeutics: OUP Oxford; 3rd edition 2012. p. 123-48.

54. Vander Heiden MG, Cantley LC, Thompson CB. Understanding the Warburg effect: the metabolic requirements of cell proliferation. Science 2009; 324: 1029-33.

55. Alimova IN, Liu B, Fan Z, Edgerton SM, Dillon T, Lind SE, et al. Metformin inhibits breast cancer cell growth, colony formation and induces cell cycle arrest in vitro. Cell Cycle 2009; 8: 909-15.

56. Stancu C, Sima A. Statins: mechanism of action and effects. J Cell Mol Med 2001; 5: 378-87.

57. Mueck AO, Seeger H, Wallwiener D. Effect of statins combined with estradiol on the proliferation of human receptor-positive and receptor-negative breast cancer cells. Menopause 2003; 10: 332-6.

58. Campbell MJ, Esserman LJ, Zhou Y, Shoemaker M, Lobo M, Borman E, et al. Breast cancer growth prevention by statins. Cancer Res 2006; 66: 8707-14.

59. Laufs U, Liao JK. Direct vascular effects of HMG-CoA reductase inhibitors. Trends Cardiovasc Med 2000; 10: 143-8.

60. Mason RP, Walter MF, Jacob RF. Effects of HMG-CoA reductase inhibitors on endothelial function: role of microdomains and oxidative stress. Circulation 2004; 109(Suppl 1): II34-41.

61. Blais L, Desgagne A, LeLorier J. 3-Hydroxy-3-methylglutaryl coenzyme A reductase inhibitors and the risk of cancer: a nested casecontrol study. Arch Intern Med 2000; 160: 2363-8.

62. Boudreau DM, Gardner JS, Malone KE, Heckbert SR, Blough DK, Daling JR. The association between 3-hydroxy-3-methylglutaryl conenzyme A inhibitor use and breast carcinoma risk among 
postmenopausal women: a case-control study. Cancer 2004; 100: 2308-16.

63. Cauley JA, Zmuda JM, Lui LY, Hillier TA, Ness RB, Stone KL, et al. Lipid-lowering drug use and breast cancer in older women: a prospective study. J Womens Health (Larchmt) 2003; 12: 749-56.

64. Katz MS. Therapy insight: Potential of statins for cancer chemoprevention and therapy. Nat Clin Pract Oncol 2005; 2: 82-9.

65. Beck P, Wysowski DK, Downey W, Butler-Jones D. Statin use and the risk of breast cancer. J Clin Epidemiol 2003; 56: 280-5.
66. Kaye JA, Meier CR, Walker AM, Jick H. Statin use, hyperlipidaemia, and the risk of breast cancer. Br J Cancer 2002; 86: 1436-9.

67. Bonovas S, Filioussi K, Tsavaris N, Sitaras NM. Use of statins and breast cancer: a meta-analysis of seven randomized clinical trials and nine observational studies. J Clin Oncol 2005; 23: 8606-12.

68. Garwood ER, Kumar AS, Baehner FL, Moore DH, Au A, Hylton N, et al. Fluvastatin reduces proliferation and increases apoptosis in women with high grade breast cancer. Breast Cancer Res Treat 2010; 119: 137-44. 